\title{
General Optimization Model of Modular Equipment Selection and Serialization for Shale Gas Field
}

\author{
Bingyuan Hong ${ }^{1 *}$, Xiaoping $\mathrm{Li}^{2 *}$, Xuemeng Cui ${ }^{2}$, Jingjing $\mathrm{GaO}^{3}, \mathrm{Yu} \mathrm{Li}^{4}$, Jing Gong ${ }^{2}$ and \\ Huanying Liu ${ }^{1}$
}

${ }^{1}$ School of Petrochemical Engineering and Environment, Zhejiang Ocean University, Zhoushan, China, ${ }^{2}$ National Engineering Laboratory for Pipeline Safety/ MOE Key Laboratory of Petroleum Engineering/ Beijing Key Laboratory of Urban Oil and Gas Distribution Technology, China University of Petroleum-Beijing, Beijing, China, ${ }^{3}$ Sinopec Qingdao Refining and Chemical CO. LTD, Qingdao, China, ${ }^{4}$ China National Oil and Gas Exploration and Development Corporation, Beijing, China

\section{OPEN ACCESS}

Edited by: Jiang Bian,

China University of Petroleum, China

Reviewed by:

Yiming Zhao,

Dalian University of Technology, China

Dongxu Sun,

Liaoning Shihua University, China

Suyang Zhu,

Southwest Petroleum University,

China

*Correspondence:

Bingyuan Hong hongby@zjou.edu.cn Xiaoping $\mathrm{LI}$

Ixpmpf@cup.edu.cn

Specialty section:

This article was submitted to Advanced Clean Fuel Technologies,

a section of the journal

Frontiers in Energy Research

Received: 19 May 2021 Accepted: 15 June 2021

Published: 30 June 2021

Citation:

Hong B, LiX, CuiX, Gao J, LiY, Gong J and Liu H (2021) General Optimization Model of Modular Equipment Selection and Serialization for Shale Gas Field.

Front. Energy Res. 9:711974.

doi: 10.3389/fenrg.2021.711974
The potential technical and economic advantages and flexible operability of modular equipment make it increasing widely used in gas field production and development. In addition to considering the manufacturing process, the selection and serialization of modular equipment should be made according to the productivity prediction of a gas well, so as to meet the field demand to the greatest extent and enhance the flexibility of gathering and transportation system. This article proposes a method to determine the use planning of modular equipment in shale gas field. Considering the processing capacity, processing cost, floor area, construction cost of modular equipment, and the changes of market supply and demand, an optimization model is established. On the basis of the abovementioned model, the method of serialization of modular equipment is proposed. The effectiveness of the model is verified by an actual case study. It is proved that the model can optimize the layout of modular equipment, make the modular equipment run efficiently and economically, reduce costs, and increase efficiency. This study provides a reference for optimizing the equipment management strategy and promoting green production practice of shale gas production.

Keywords: shale gas, MILP model, modular equipment, capacity selection, equipment serialization

\section{INTRODUCTION}

Shale gas revolution has greatly promoted the transformation of energy structure Gao and You (2017b), which is of great strategic significance to the goal of carbon neutrality and has been widely concerned (Fan et al., 2021; Shi et al., 2021). However, with the rapid decline of shale gas production capacity, the load rate and various operating conditions of the equipment are constantly changing (Hong et al., 2019; 2020a). Traditional fixed equipment is difficult to disassemble once installed, which makes it lack flexibility to adapt to the changes of production capacity, and it is difficult to work continuously in the efficient working area (Zhou et al., 2019). On the contrary, due to the characteristics of small floor area, convenient disassembly and assembly, being easy to move, and low development risk, modular equipment can better adapt to the changing production capacity (Gao and You, 2017a; Yang and You, 2018), showing great potential, and is expected to be widely used in all aspects of oil and gas development, production, and processing (Yin et al., 2018; Hong et al., 2020b).

Many scholars are committed to the economic research and process design of modular equipment. Baldea et al. (2017) summarized the status, challenges, and opportunities of modular 
manufacturing processes and proposed the concept of value density to represent the geographical distribution of raw materials or markets absorbing products. The opportunity of modular manufacturing is related to value density, and it can reduce the scale of unit operation and improve efficiency by means of process strengthening. Tian et al. (2018) conducted a research on the most advanced method of process enhancement, process systems engineering, focusing on some recent advances in the modeling, design, and synthesis of enhanced systems, which can be used to develop larger-scale modularization equipment. Demirel et al. (2017) designed a process intensification method based on the basic components, which is opposite to the traditional flow chart. The method establishes a single mixed integer nonlinear optimization model to solve the problem for systematic process design and intensification. In addition, the economics and flexibility of a modular chemical plant is compared with traditional large-scale factories by investigating net present value (Lier and Grünewald, 2011). Palys et al. (2019) studied the economic benefits of traditional continuous and modular wind power ammonia production and proved the advantages of modular equipment from a quantitative perspective. Compared with continuous production, modular production leads to lower supply chain costs and more renewable energy integration. A new process obtaining input from the relatively old natural-gas-based process is specially designed for small-scale ammonia production and is combined with the recently developed dual fluidized bed technology for biomass feedstock. The results show that the small-scale ammonia plant based on biomass has more technical and economic advantages (Arora et al., 2016). Technical and economic analysis and environmental impact analysis were carried out on the four shale gas monetization schemes, and their economic and environmental benefits under the same conditions were systematically compared (Yang and You, 2018). The results show that modular methanol production is more economically competitive than traditional shale gas processing, although it will cause a higher environmental impact.

The above mentioned research shows that modular equipment has unique economic advantages and flexible operability, which provides a new perspective for the use of modular equipment. However, there is little research on the optimization methods of modular equipment selection and serialization in shale gas field. In the production of shale gas field, the layout combination and operation scheme of modular equipment can be optimized according to the change of gas field production, so as to realize efficient and economic operation. The serialization of the processing capacity of modular equipment refers to the scientific planning of the processing capacity sequence of the same modular equipment. The purpose is to optimize, simplify, and stereotype the bulk, common, and repetitive production and construction content, which is conducive to reducing engineering costs, improving the interoperability of equipment, and at the same time, facilitating production management. Therefore, a method to select and serialize modular equipment based on changes in gas well productivity needs to be further studied.

Therefore, this article proposes a method to determine the use planning of modular equipment in shale gas field. Considering the processing capacity, processing cost, floor area, construction cost of modular equipment, and the changes of market supply and demand, an optimization model is established. On the basis of the abovementioned model, the method of serialization of modular equipment is proposed. The effectiveness of the model is verified by an actual case study. It is proved that the model can optimize the layout of modular equipment, make the modular equipment run efficiently and economically, reduce costs, and increase efficiency.

The structure of this article is as follows. In Problem Description, the optimization problem is explained in detail, including the basic parameters and decision variables. Mathematical Model shows the proposed optimization mathematical model. Case Study verifies the practicability of the proposed optimization model through case analysis and compares the modular and traditional methods. Finally, the conclusion and future research prospects are drawn.

\section{PROBLEM DESCRIPTION}

As mentioned above, modular equipment has more flexible processing capabilities and can achieve changes in processing scale. The production capacity of shale gas has changed drastically, with high production output in the initial stage and then rapidly declining. Therefore, modularization is more promising for the stable production of shale gas. The main purpose of this study is to propose an optimization model to determine the optimal selection and serialization of modular equipment for shale gas field. However, it should be noted that the productivity curve is considered in this model, which is applicable to all oil and gas fields and is universal, not limited to shale gas fields. The problems to be solved are stated as follows, taking the gas field as an example:

As mentioned above, modular equipment has potential technical and economic advantages and can be used in gas field development. As shown in Figure 1, for the same gas field, the gas reservoir engineering provides production capacity prediction, and there is a variety of different modular equipment usage plans throughout the life cycle of gas field development. Specifically, scheme 1 uses modular equipment with two processing capacity specifications of $70,000 \mathrm{~m}^{3} /$ day and $200,000 \mathrm{~m}^{3} /$ day, while scheme 2 uses modular equipment with three processing capacity specifications of $20,000 \mathrm{~m}^{3} /$ day, $50,000 \mathrm{~m}^{3} /$ day, and $100,000 \mathrm{~m}^{3} /$ day. The adjustment of processing capacity is carried out through the purchase and sale of equipment in both schemes. Among many schemes, there must be one that can maximize the profit of the gas field. Decision makers need to decide how to replan and deploy modular equipment based on the time-varying production capacity forecast and market demand.

The processing capacity sequence of the modular equipment must be both economical and versatile. Different equipment have their own economic boundaries, so the capacity series of equipment should be made according to the changes of productivity curves of different gas fields, and the customization and universality of equipment should be chosen 

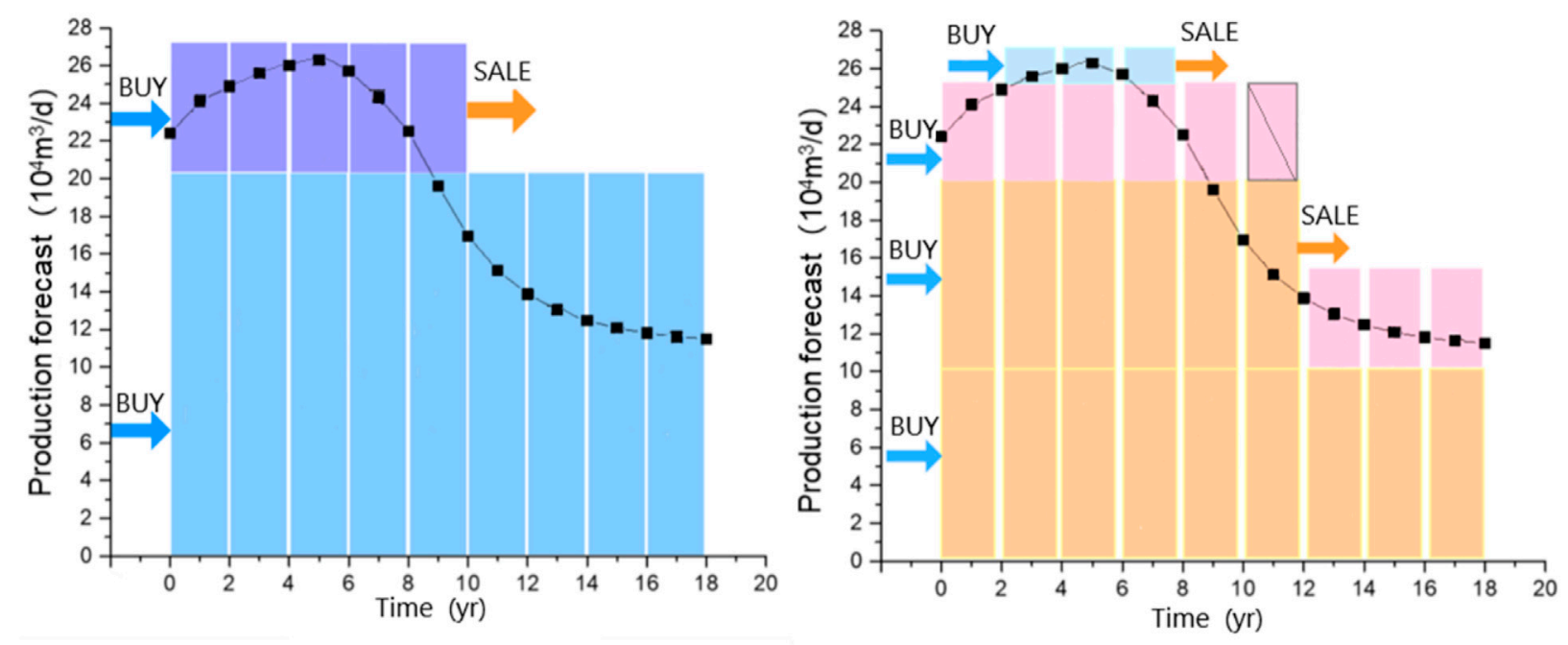

Maximum processing capacity of equipment

$200000 \mathrm{~m}^{3} / \mathrm{d}$

$70000 \mathrm{~m}^{3 / \mathrm{d}}$ $100000 \mathrm{~m}^{3} / \mathrm{d}$

$50000 \mathrm{~m}^{3} / \mathrm{d}$ $20000 \mathrm{~m}^{3} / \mathrm{d}$ Idle

FIGURE 1 | Schematic diagram of the use scheme for different series of modular equipment.

to realize the economy and universality of equipment. For example, if a natural gas flow of $10,000 \mathrm{~m}^{3} / \mathrm{d}$ needs to be processed, it is more economical to choose equipment with a rated capacity of $10,000 \mathrm{~m}^{3} / \mathrm{d}$ than equipment with a rated capacity of $50,000 \mathrm{~m}^{3} / \mathrm{d}$. Universality means that a single piece of equipment in the serialized equipment should be more commonly used, and the serialized equipment as a whole means that, through a reasonable combination, it should be able to cover the needs of common capacity planning schemes. For example, the need to process a flow rate of $500,000 \mathrm{~m}^{3} / \mathrm{d}$ of natural gas can be achieved by two pieces of equipment with a rated capacity of $250,000 \mathrm{~m}^{3} / \mathrm{d}$ or by 50 pieces of equipment with a rated capacity of $10,000 \mathrm{~m}^{3} / \mathrm{d}$, while the latter will obviously cause maintenance problems for site personnel. Therefore, it is necessary to carry out research to seek the optimal selection and serialization of modular equipment in oil and gas field development, so as to improve the economic benefits of oil and gas field development.

In order to facilitate modeling and improve the efficiency of model solving, the following assumptions are proposed:

(1) The whole life cycle of gas field development is divided into a series of equal length discrete unit periods. It is assumed that the gas field production does not change in the unit period. (2) The equipment is allowed to run beyond the scheduled life, but the equipment running beyond the scheduled life will incur additional operation and maintenance costs.

(3) In this work, the purchase, sale, disassembly, and assembly of the equipment can be completed within a period of time. It is assumed that each equipment can be manufactured in the current period and no appointment is required in advance.

(4) The variable operating cost depends on the gas processing capacity and unit processing cost, and it is considered that the unit processing cost of similar modular equipment is the same.
Given:

(1) Productivity information: the gas well production proposed by gas well production prediction

(2) Economic information: price of qualified natural gas in different periods

(3) Equipment information: processing capacity, purchase, installation, disassembly, operation, and overdue maintenance cost of modular equipment with different processing capacities

Determine:

(1) Equipment usage planning: the equipment type, number, operation status (actual processing capacity) and installation, disassembly, and sale measures in different periods

(2) Economic cost: the net present value in different periods, the equipment purchase, sale, disassembly, operation, and over-term maintenance costs in different periods

\section{MATHEMATICAL MODEL}

All the known parameters involved in the proposed model are represented by symbols composed of lowercase letters, and variables are represented by symbols beginning with capital letters. $i \in(1, \ldots, I)$ stands for the set of equipment specification types, $e \in(1, \ldots, E)$ represents the number set of equipment, and $t, t b \in(1, \ldots, T)$ is used to define the time periods over the given planning horizon.

\section{Objective Function}

Net present value is an important technical and economic index to evaluate the profitability of investment. Therefore, the 
objective function is to maximize the net present value in the whole development cycle.

$$
N P V=\sum_{t \in T} C_{t} \times(1+r)^{1-t},
$$

where $N P V$ is the net present value, $C_{t}$ is the cash flow in period $t$, and $r$ is the discount rate.

\section{Model Constraints Economic Constraints}

The cash flow $\left(\mathrm{C}_{t}\right)$ in period $t$ consists of six parts: income from selling qualified products $\left(\operatorname{Igas}_{t}\right)$, income from selling used modular equipment $\left(I e q u_{t}\right)$, expenses for purchasing modular equipment $\left(E b u y_{t}\right)$, expenses for installing modular equipment $\left(\right.$ Eins $\left._{t}\right)$, expenses for dismantling modular equipment $\left(\right.$ Edis $\left._{t}\right)$, expenses for operating modular equipment $\left(\right.$ Eope $\left._{t}\right)$, and expenses for maintenance of overdue modular equipment $\left(\right.$ Emai $\left._{t}\right)$.

$$
\begin{aligned}
C_{t}= & \text { Igas }_{t}+\text { Iequ }_{t}-\text { Ebuy }_{t}-\text { Eins }_{t}-\text { Edis }_{t}-\text { Eope }_{t} \\
& - \text { Emai }_{t} \quad \forall t \in T .
\end{aligned}
$$

The income from selling qualified products $\left(\operatorname{Igas}_{t}\right)$ is equal to the price $\left(\right.$ pgas $\left._{t}\right)$ multiplied by the output. The output is equal to the total gas flow rate received by all equipment $\left(q_{t}\right)$ multiplied by the ratio of the equipment outlet flow rate and the inlet flow rate $(r a)$.

$$
\operatorname{Igas}_{t}=\operatorname{pgas}_{t} \cdot q_{t} \cdot r a \quad \forall t \in T .
$$

The income from selling used modular equipment $\left(I e q u_{t}\right)$ is the sum of the selling income $\left(\right.$ EIeuq $\left._{t, i, e}\right)$ of each $i$-type $e$-numbered equipment. $e b_{i, e}$ is the origin purchase price of $i$-type $e$-numbered equipment. Service life affects equipment depreciation, and $d e q_{t, t b}$ is employed to characterize the selling coefficient. The binary variable $\left(B s_{t, i, e, t b}\right)$ determines whether $i$-type $e$-numbered equipment is to be sold or not. If the $i$-type $e$-numbered equipment purchased in $t b$ period is sold in $t$ period, then $B s_{t, i, e, t b}=1$; otherwise, $B s_{t, i, e, t b}=0$.

$$
\begin{gathered}
\operatorname{Iequ}_{t}=\sum_{i \in I} \sum_{e \in E} \text { EIequ }_{t, i, e} \quad \forall t \in T, \\
\text { EIequ }_{t, i, e}=\sum_{t b \leq t} e b_{i, e} \times B s_{t, i, e, t b} \times d e q_{t, t b} \quad \forall t \in T, i \in I, e \in E .
\end{gathered}
$$

The expenses for purchasing modular equipment $\left(E b u y_{t}\right)$ are the sum of the purchase cost of each $i$-type $e$-numbered equipment $\left(E E b u y_{t}\right)$. The binary variable $\left(B b_{t, i, e}\right)$ determines whether to buy $i$-type $e$-numbered equipment. If the $i$-type $e$-numbered equipment purchased is purchased in $t$ period, then $B b_{t, i, e}=1$; otherwise, $B b_{t, i, e}=0$.

$$
\begin{gathered}
\text { Ebuy }_{t}=\sum_{i \in I} \sum_{e \in E} E_{e E b u y} y_{t, i, e} \quad \forall t \in T, \\
\text { EEbuy }_{t, i, e}=e b_{i, e} \times B b_{t, i, e} \forall t \in T, i \in I, e \in E .
\end{gathered}
$$

Installation is required when buying new equipment, and disassembly is required when selling used equipment. Similarly, the expenses for installing modular equipment
(Eins $)_{t}$ and the expenses for dismantling modular equipment $\left(E d i s_{t}\right)$ are the sum of according cost of each $i$-type $e$-numbered equipment. eins $s_{i, e}$ is the cost of installation, and $e d i s_{i, e}$ is the cost of disassembly.

$$
\begin{gathered}
\text { Eins }_{t}=\sum_{i \in I} \sum_{e \in E} \text { eins }_{i, e} \times B b_{t, i, e} \forall t \in T, \\
\text { Edis }_{t}=\sum_{i \in I} \sum_{e \in E t b \leq t} \sum_{e d i s_{i, e}} \cdot B s_{t, i, e, t b} \forall t \in T .
\end{gathered}
$$

The expenses for operating modular equipment $\left(E o p e_{t}\right)$ are the sum of ones of each $i$-type $e$-numbered equipment $\left(E E o p e_{t}\right)$, which is related to the actual flow rate of the equipment $\left(Q a_{t, i, e}\right) . \alpha_{i, e}$ is the processing cost per unit of original natural gas, and $\beta_{i, e}$ is the fixed cost of the equipment. $B_{t, i, e, t b}$ is a binary variable of the device state. If the $i$-type $e$-numbered equipment purchased in period $t b$ still exists in period $t$, then $B_{t, i, e, t b}=1$; otherwise, $B_{t, i, e, t b}=0$.

$$
\begin{aligned}
& \text { Eope }_{t}=\sum_{i \in I} \sum_{e \in E} E_{E o p e_{t, i, e}} \forall t \in T, \\
& \text { EEope }_{t, i, e}=\alpha_{i, e} \times Q a_{t, i, e}+\beta_{i, e} \times \sum_{t b \leq t} B_{t, i, e, t b} \quad t \in T, i \in I, e \in E .
\end{aligned}
$$

The expenses for maintenance of overdue modular equipment $\left(\right.$ Emai $\left._{t}\right)$ depend on the amount of equipment that needs to be repaired and maintained. $e m t_{i, e}$ is the base cost of equipment maintenance, and $m e q_{t, t b}$ is employed to characterize the maintenance coefficient; the longer the service life, the higher the cost of equipment maintenance.

$$
\begin{gathered}
\text { Emai }_{t}=\sum_{i \in I} \sum_{e \in E} E_{e \in m a i_{t, i, e}} \forall t \in T, \\
E_{E m a i_{t, i, e}}=\sum_{t b \leq t} e m t_{i, e} \times B_{t, i, e, t b} \times m_{e q} q_{t, t b} t \in T, i \in I, e \in E .
\end{gathered}
$$

\section{Equipment Capacity Constraints}

Each equipment has its own rated flow $\left(q e c a p_{i, e}\right)$ and is allowed to work within a certain range of rated flow. $a q_{\max }$ and $a q_{\min }$ are flow coefficients used to represent the fluctuation range of relative rated capacity. $B_{t, i, e, t b}$ is a binary variable of the device state. If the $i$-type $e$-numbered equipment is purchased in period $t b$ and is working in period $t$, then $B u_{t, i, e, t b}=1$; otherwise, $B u_{t, i, e, t b}=0$.

$$
\begin{aligned}
& Q a_{t, i, e} \leq a q_{\text {max }} \cdot \operatorname{qecap}_{i, e} \cdot \sum_{t b \leq t} B u_{t, i, e, t b} \forall t \in T, i \in I, e \in E, \\
& Q a_{t, i, e} \geq a q_{\text {min }} \cdot \operatorname{qecap}_{i, e} \cdot \sum_{t b \leq t} B u_{t, i, e, t b} \forall t \in T, i \in I, e \in E .
\end{aligned}
$$

The sum of the actual processing capacity of each equipment is equal to the gas field production.

$$
\sum_{i \in I} \sum_{e \in E} Q a_{t, i, e}=q_{t} \forall w \in W, t \in T .
$$

The total footprint of the equipment should be smaller than the available area of the gas field $\left(s w_{\max }\right)$. 


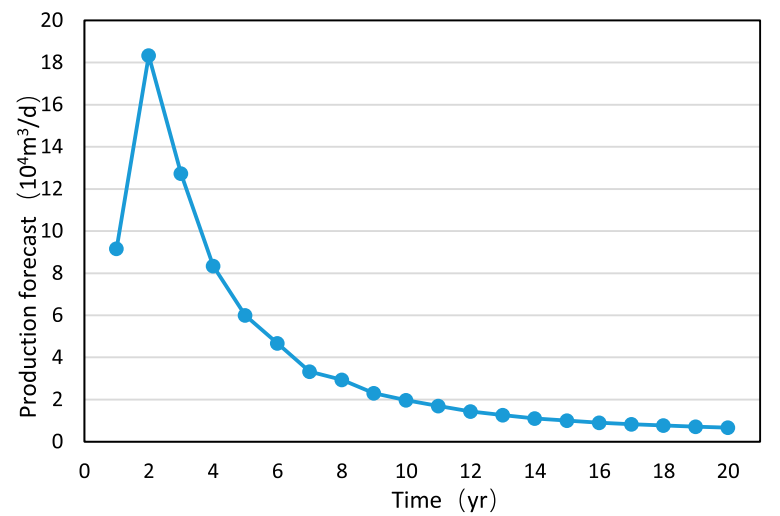

FIGURE 2 | The gas production forecast of the gas well.

$$
\sum_{i \in I} \sum_{e \in E t b \leq t} \sum_{t, i, e, t b} \cdot e s_{i, e} \leq s w_{\max }
$$

\section{Equipment Selection Constraints}

Two subscripts are used to indicate the time state of the equipment; $t b$ indicates the time the equipment was purchased, and $t$ indicates the current time.

When $t<t b$, there is no equipment that has been purchased, so there is no equipment that can be sold.

$$
\begin{gathered}
B_{t, i, e, t b}=B b_{t, i, e} \forall t, t b \in T, i \in I, e \in E, \\
B s_{t, i, e, t b}=0 \forall t, t b \in T, i \in I, e \in E .
\end{gathered}
$$

When $t=t b$, the equipment is new at this time.

$$
B_{t, i, e, t b}=B b_{t, i, e} \forall t, t b \in T, i \in I, e \in E \text {. }
$$

When $t>t b$, the current number of equipment $\left(B_{t, i, e, t b}\right)$ is equal to the equipment owned in the previous period $\left(b_{t-1, i, e, t b}\right)$ minus the equipment sold at the moment $\left(B s_{t, i, e, t b}\right)$.

$$
B_{t, i, e, t b}=B_{t-1, i, e, t b}-B s_{t, i, e, t b} \forall t, t b \in T, i \in I, e \in E .
$$

Each device is purchased and sold at most once in the entire life cycle.

$$
\begin{gathered}
\sum_{t \in T} B b_{t, i, e} \leq 1 \forall i \in I, e \in E, \\
\sum_{t \in T} \sum_{t b \leq t} B s_{t, i, e, t b} \leq 1 \quad \forall i \in I, e \in E .
\end{gathered}
$$

When $t=t 1$, no equipment is allowed to be sold in the first cycle.

$$
B s_{t, i, e, t b}=0 \forall t, t b \in T, i \in I, e \in E .
$$

In addition, the sold equipment must be existing.

$$
B_{t-1, i, e, t b} \geq B s_{t, i, e, t b} \forall t, t b \in T, i \in I, e \in E .
$$

An existing equipment may be in use or may be out of service.

$$
B u_{t, i, e, t b} \leq B_{t, i, e, t b} .
$$

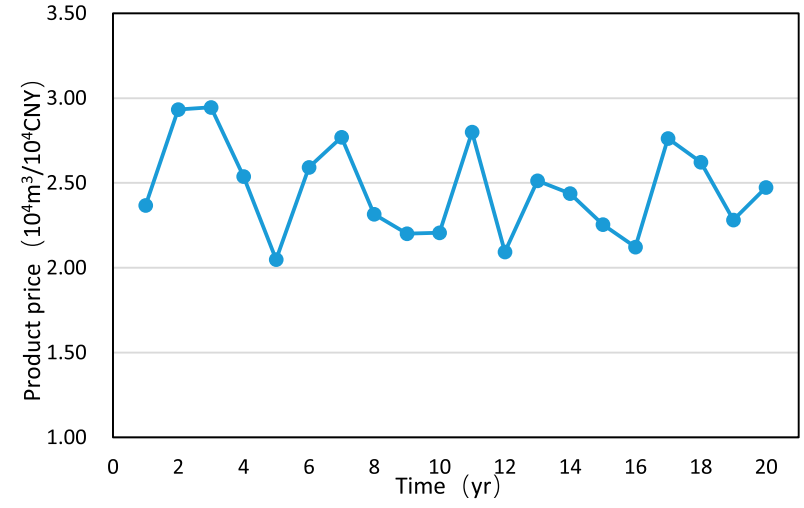

FIGURE 3 | The price of qualified natural gas.

\section{CASE STUDY}

Taking an actual gas field in Sichuan China as an example, equipment selection and serialization was carried out and compared with traditional methods to verify the effectiveness of the model. The program is written with gams software, and the commercial solver Gurobi is called to solve the problem, running on a 4-core 8-thread Intel CPU i7-6700 $(2.6 \mathrm{GHz})$ and $16 \mathrm{~GB}$ memory computer. It is important to note that the optimization model proposed in this article has no special limitation on the type of production capacity prediction and equipment type, it is universal, and its application is not limited to any specific type of oil and gas fields.

\section{Basic Parameters}

The gas field is located in a certain place in Sichuan. According to the gas production forecast of the gas well, the gas production of the gas field changes with time, as shown in Figure 2. The output of the block reached its peak in the early stage of development and then declined rapidly. In addition, the price of qualified natural gas is shown in Figure 3.

Modular TEG dehydration equipment is needed in the gas gathering station, and the annual fixed operating cost of each equipment is $2.5 \%$ of the purchase cost. The variable operating cost depends on the gas processing capacity and unit processing cost, and it is considered that the unit processing cost of similar modular equipment is the same. According to production practice, the purchase cost of $50,000 \mathrm{~m}^{3} / \mathrm{d}$ modular TEG dehydration equipment is $500,000 \mathrm{CNY}$, and the purchase cost of the same type of modular equipment of other scales is calculated according to the six-tenth rule widely used in the chemical industry (Hong et al., 2020b). In addition, based on data from gas field, the purchase cost of traditional fixed treatment equipment is 1.3 times that of modular equipment, and other cost parameters are the same as those for modular equipment. Therefore, equipment parameters are as shown in Table 1.

\section{Equipment Selection}

The results of the following equipment selection analysis show the optimized usage of the equipment. It can be seen that, among 
TABLE 1 | Equipment parameters.

\begin{tabular}{|c|c|c|c|c|c|c|}
\hline $\begin{array}{l}\text { Modular } \\
\text { equipment } \\
\text { type }\end{array}$ & $\begin{array}{c}\text { Rated processing } \\
\text { capacity }\left(q e c a p_{i, e}\right) \\
{\left[10^{4} \mathrm{~m}^{3} / \mathrm{d}\right]}\end{array}$ & $\begin{array}{l}\text { Equipment } \\
\text { purchase } \\
\text { cost }\left(c e b_{i, e}\right) \\
{\left[10^{4} \mathrm{CNY}\right]}\end{array}$ & $\begin{array}{c}\text { Variable operating } \\
\text { cost }\left(a_{i, e}\right)\left[10^{4} \mathrm{CNY} /\right. \\
\left.10^{4} \mathrm{~m}^{3}\right]\end{array}$ & $\begin{array}{c}\text { Fixed operating } \\
\text { cost }\left(b_{i, e}\right) \\
{\left[10^{4} \mathrm{CNY} / \mathrm{yr}\right]}\end{array}$ & $\begin{array}{c}\text { Installation and } \\
\text { disassembly expenses } \\
\left(\text { ceins }_{i, e}, \text { cedis }_{i, e}\right) \\
{\left[10^{4} \mathrm{CNY}\right]}\end{array}$ & $\begin{array}{c}\text { Floor } \\
\text { area } \\
\left(e s_{i, e}\right) \\
{\left[\mathrm{m}^{2}\right]}\end{array}$ \\
\hline i1 & 1 & 19.04 & 0.003 & 0.05 & 0.38 & 12 \\
\hline i2 & 2 & 28.85 & 0.003 & 0.07 & 0.58 & 15 \\
\hline i3 & 3 & 36.80 & 0.003 & 0.09 & 0.74 & 21 \\
\hline i4 & 4 & 43.73 & 0.003 & 0.11 & 0.87 & 27 \\
\hline ¡5 & 5 & 50.00 & 0.003 & 0.13 & 1.00 & 34 \\
\hline 16 & 6 & 55.78 & 0.003 & 0.14 & 1.12 & 37 \\
\hline$i 7$ & 7 & 61.19 & 0.003 & 0.15 & 1.22 & 41 \\
\hline i8 & 8 & 66.29 & 0.003 & 0.17 & 1.33 & 44 \\
\hline i9 & 9 & 71.14 & 0.003 & 0.18 & 1.42 & 49 \\
\hline ¡10 & 10 & 75.79 & 0.003 & 0.19 & 1.52 & 55 \\
\hline i11 & 11 & 80.25 & 0.003 & 0.20 & 1.60 & 58 \\
\hline i12 & 12 & 84.55 & 0.003 & 0.21 & 1.69 & 62 \\
\hline i13 & 13 & 88.71 & 0.003 & 0.22 & 1.77 & 66 \\
\hline i14 & 14 & 92.74 & 0.003 & 0.23 & 1.85 & 67 \\
\hline i15 & 15 & 96.66 & 0.003 & 0.24 & 1.93 & 72 \\
\hline i16 & 16 & 100.48 & 0.003 & 0.25 & 2.01 & 74 \\
\hline$i 17$ & 17 & 104.20 & 0.003 & 0.26 & 2.08 & 77 \\
\hline i18 & 18 & 107.83 & 0.003 & 0.27 & 2.16 & 81 \\
\hline ¡19 & 19 & 111.39 & 0.003 & 0.28 & 2.23 & 83 \\
\hline i20 & 20 & 114.87 & 0.003 & 0.29 & 2.30 & 86 \\
\hline
\end{tabular}
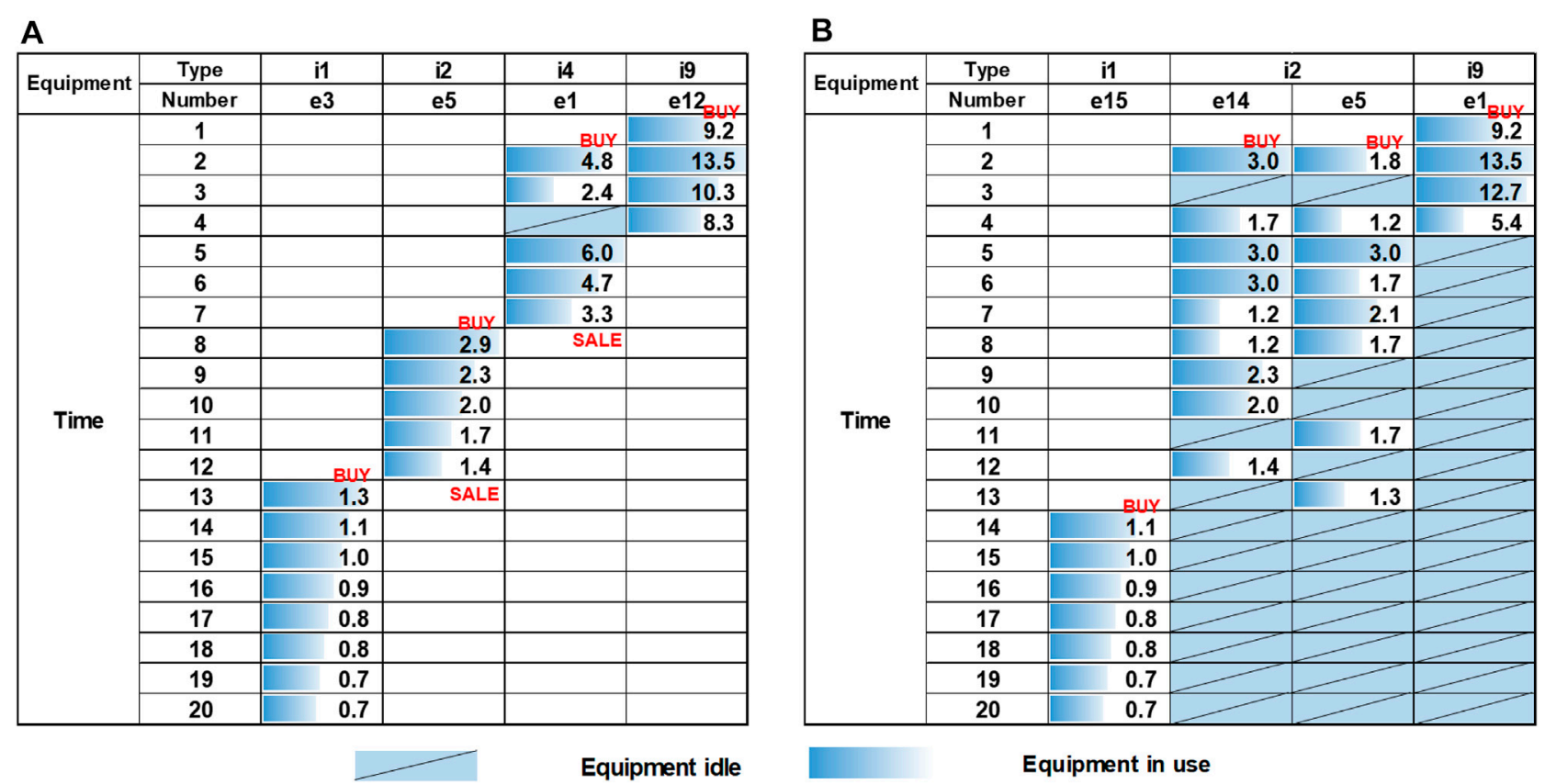

FIGURE 4 | The selection and usage of equipment in the whole time period. (A) Modular equipment and (B) traditional equipment.

the 20 different processing capacity equipment, four modular equipment, (i1, e3), (i2, e5), (i4, e1), and (i9, e12), are selected. As shown in Figure 4, each number in the grid represents the actual processing flowrate of a modular equipment, and the shade intensity reflects the equipment load rate, that is, the ratio of the actual processing flowrate to the maximum processing flowrate. For more information on the definition and calculation method of load rate, it is recommended to refer to our previous research (Hong et al., 2020b). The load rate of modular equipment is greatly improved from 0.20 to 0.62 compared with traditional fixed equipment. Each modular equipment is allocated to different locations according to 


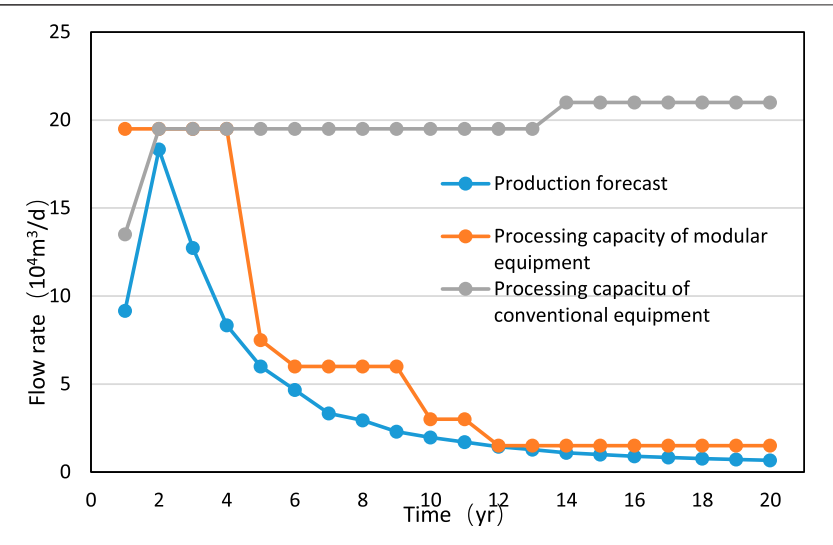

FIGURE 5 | The processing capacity of equipment and gas field production.

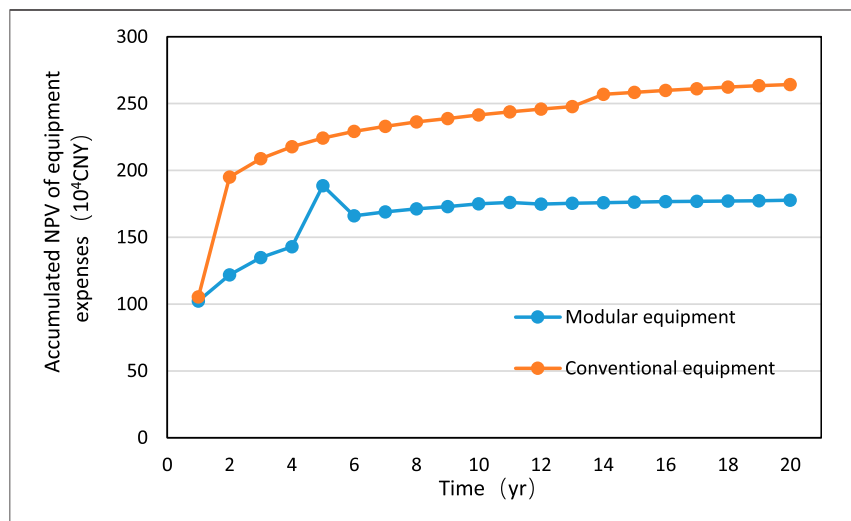

FIGURE 6 | Accumulated net present value of equipment expenses.

scheduling requirements. Among them, equipment (i2, e5), (i4, e1), and (i9, e12) are sold because they cannot be used, which can save investment. However, the traditional fixed equipment cannot be sold, so it can only stop operating, resulting in idle processing capacity.

The relationship of the equipment processing capacity and the gas field production in each block is shown in Figure 5. When the output of the gas source began to decline after the second period, the traditional fixed equipment has a lot of redundancy in processing capacity because it is not detachable. On the contrary, modular equipment can avoid this problem through the sale of equipment. The processing capacity of modular equipment changes throughout the life cycle of the gas field and is closely related to the change of gas production, so it is more flexible and has the ability to adapt to the fluctuation of gas field production. It is foreseeable that if there are multiple gas fields, equipment scheduling among multiple gas fields will help further increase the flexibility of production and reduce costs.

Figure 6 shows the accumulated net present value of equipment expenses using modular equipment and traditional fixed equipment, while the accumulated net present value of

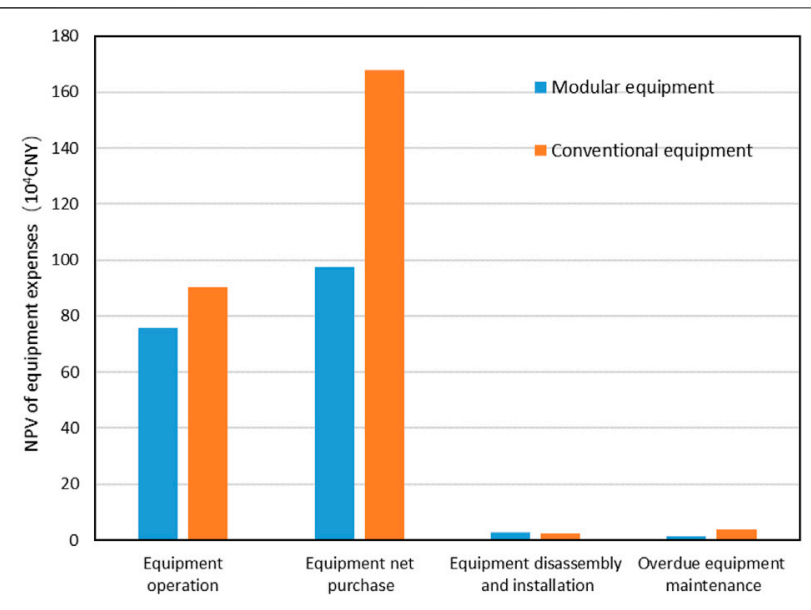

FIGURE 7 | Expenses of modular equipment and traditional fixed equipment.

equipment expenditure of modular equipment is less than that of conventional equipment.

The specific expenses of modular equipment and traditional fixed equipment are shown in Figure 7. The biggest expenditure is equipment operating cost and equipment purchase cost, while the proportion of equipment installation is very small. The economy of modular equipment is mainly reflected in the sharp reduction of equipment net purchase cost caused by the equipment resale.

\section{Equipment Serialization}

The processing capacity sequence of the modular equipment must be both economical and universal. The optimization model of modular equipment capacity selection proposed in this article is precisely to determine the modular equipment arrangement and operation scheme with the best economic efficiency as the goal, but the universality of the equipment use scheme needs further analysis. In general, the serialization of capacity specifications should be balanced between universality and economy. An analysis method is proposed in the following.

Figure 8 shows four types of common gas field block productivity planning schemes, each with multiple production characteristics. Type 1, 2, 3, and 4 are the common productivity planning schemes in the early centralized development mode of unconventional gas field, in the early stage of long-term stable production development mode, in the whole cycle of long-term stable production development mode, and in the late stage of long-term stable production development mode, respectively.

Figure 9 shows the optimal serialization of modular equipment for the abovementioned four types of productivity planning schemes using the proposed optimization model. It can be seen that all serializations are a combination of several smallscale equipment and one medium processing capacity equipment or large-scale processing equipment.

In order to define the universality of the processing capacity sequence, the use frequency of modular equipment in the abovementioned optimal scheme is analyzed as shown in 

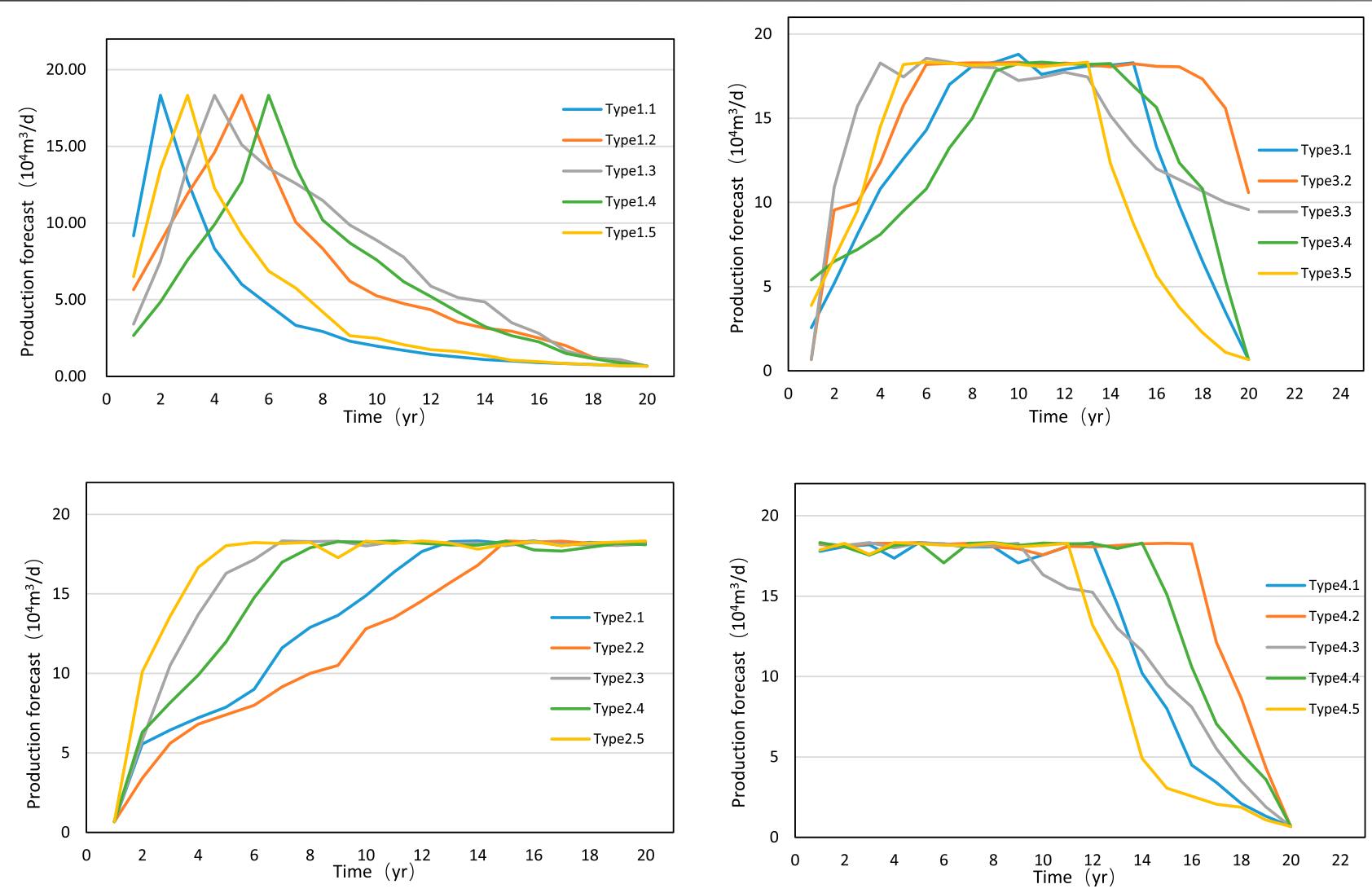

FIGURE 8 | Four types of common gas field block productivity planning schemes.

\begin{tabular}{|c|c|c|c|c|c|c|c|c|c|c|c|c|c|c|c|c|c|c|c|c|}
\hline \multirow{3}{*}{$\begin{array}{c}\text { Production } \\
\text { forecast } \\
\text { type }\end{array}$} & \multicolumn{20}{|c|}{ Number of equipment } \\
\hline & \multicolumn{7}{|c|}{ Small processing capacity } & \multicolumn{7}{|c|}{ Medium processing capacity } & \multicolumn{6}{|c|}{ Large processing capacity } \\
\hline & i1 & i2 & i3 & i4 & i5 & Total & Average & i6 & i7 & i8 & i9 & i10 & Total A & Average & i11 & i12 & i13 & i14 & Total & Average \\
\hline 1.1 & 1 & 1 & & 1 & & 3 & \multirow{20}{*}{2.3} & & & & 1 & & 1 & \multirow{20}{*}{0.6} & & & & & 0 & \multirow{20}{*}{0.4} \\
\hline 1.2 & 2 & & 1 & 1 & & 4 & & 1 & & & & & 1 & & & & & & 0 & \\
\hline 1.3 & 2 & & & & 1 & 3 & & & & 1 & & & 1 & & & & & & 0 & \\
\hline 1.4 & 2 & & 1 & 1 & & 4 & & 1 & & & & & 1 & & & & & & 0 & \\
\hline 1.5 & 1 & 1 & & & 1 & 3 & & & & & 1 & & 1 & & & & & & 0 & \\
\hline 2.1 & 1 & & & & 1 & 2 & & & & & 1 & & 1 & & & & & & 0 & \\
\hline 2.2 & 1 & & & & 1 & 2 & & & & 1 & & & 1 & & & & & & 0 & \\
\hline 2.3 & 1 & & & & 1 & 2 & & & & & 1 & & 1 & & & & & & 0 & \\
\hline 2.4 & 3 & & & & & 3 & & & & & & 1 & 1 & & & & & & 0 & \\
\hline 2.5 & 1 & & & & & 1 & & & & & & & 0 & & & 1 & & & 1 & \\
\hline 3.1 & & & & 1 & & 1 & & & & & 1 & & 1 & & & & & & 0 & \\
\hline 3.2 & 1 & & & & & 1 & & & & & & & 0 & & & 1 & & & 1 & \\
\hline 3.3 & 1 & & & & & 1 & & & & & & & 0 & & & 1 & & & 1 & \\
\hline 3.4 & 1 & & & & 1 & 2 & & & & 1 & & & 1 & & & & & & 0 & \\
\hline 3.5 & 2 & & 1 & & & 3 & & & & & & 1 & 1 & & & & & & 0 & \\
\hline 4.1 & 1 & & 1 & & & 2 & & & & & & & 0 & & & 1 & & & 1 & \\
\hline 4.2 & 1 & 1 & & & & 2 & & & & & & & 0 & & & & 1 & & 1 & \\
\hline 4.3 & 2 & 1 & & & & 3 & & & & & & & 0 & & & & 1 & & 1 & \\
\hline 4.4 & 1 & & & & 1 & 2 & & & & & & & 0 & & & & & 1 & 1 & \\
\hline 4.5 & 1 & & 1 & & & 2 & & & & & & & 0 & & & 1 & & & 1 & \\
\hline
\end{tabular}

FIGURE 9 | Optimal serialization of modular equipment. 


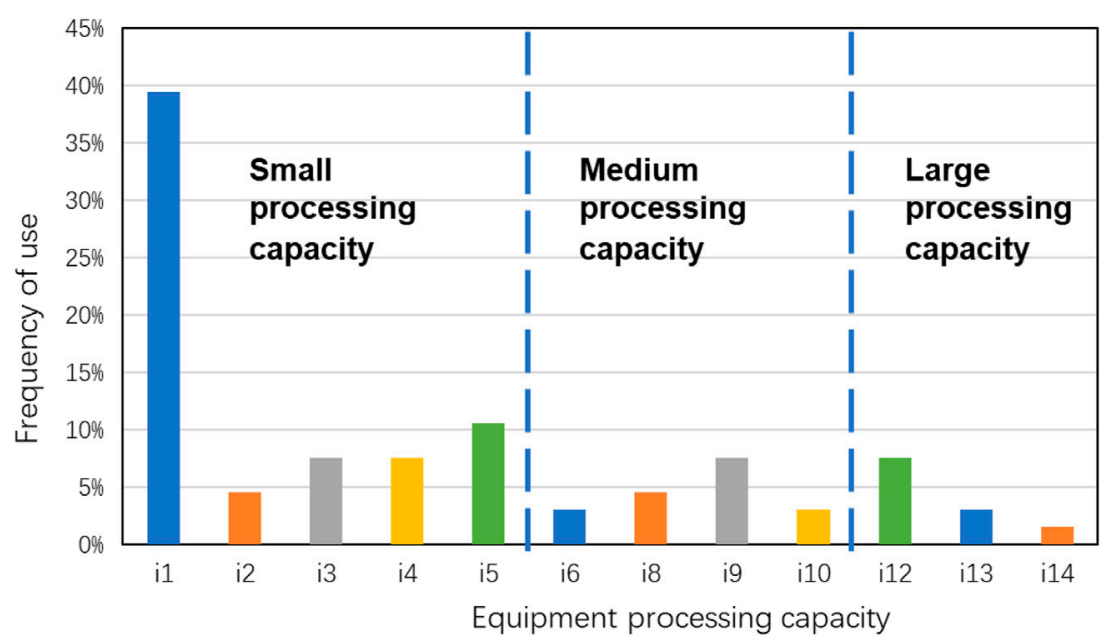

FIGURE 10 | Use frequency of modular equipment.

Figure 10. Because the small processing capacity equipment is used more frequently, the two types with the highest chosen frequency are selected, il and i5. For the medium processing capacity and the high-processing equipment, i9 and i12 are the two types with the highest chosen frequency.

Analyzing the selected equipment series, i1, i5, i9, and i12, the processing capacity corresponds to $10,000 \mathrm{~m}^{3} / \mathrm{d}, 50,000 \mathrm{~m}^{3} / \mathrm{d}$, $90,000 \mathrm{~m}^{3} / \mathrm{d}$, and $120,000 \mathrm{~m}^{3} / \mathrm{d}$, respectively. The reasonable combination of these types of equipment can cover the demand of all the abovementioned capacity planning schemes, so the selected equipment series is universal enough. Therefore, under the conditions of the economic parameters and the production mode of the gas field described in this example, the processing capacities of the final selected specific type of modular TEG dehydration equipment are $10,000 \mathrm{~m}^{3} / \mathrm{d}$, $50,000 \mathrm{~m}^{3} / \mathrm{d}, 90,000 \mathrm{~m}^{3} / \mathrm{d}$, and $120,000 \mathrm{~m}^{3} / \mathrm{d}$.

\section{CONCLUSION}

The main purpose of this study is to propose an optimization model to determine the optimal selection and serialization of modular equipment for shale gas field. Considering the processing capacity, processing cost, floor area, construction cost of modular equipment, and the changes of market supply and demand, a multiperiod optimization model is established, taking the maximum net present value as the objective function. In the modeling, the variable subscript couples the equipment type and number, which can realize the unique coding of the equipment, so as to track the use status of the specific equipment. It should be noted that the productivity curve is considered in this model, which is applicable to all oil and gas fields and is universal, not limited to shale gas fields.

An actual gas field in Sichuan, China, is employed to verify the practicability and effectiveness of the proposed model. Compared with traditional fixed equipment, modular equipment is allocated to different locations according to scheduling requirements and has the ability to adapt to the fluctuation of gas field production. The accumulated net present value of equipment expenditure of modular equipment is less than that of conventional equipment, and the load rate of modular equipment is greatly improved from 0.20 to 0.62 . On the basis of the abovementioned model, the method of serialization of modular equipment is proposed. Considering four types of common gas field block productivity planning schemes, the use frequency of different specifications modular equipment is analyzed to determine optimal equipment series; the processing capacities of the final selected specific type of modular TEG dehydration equipment are $10,000 \mathrm{~m}^{3} / \mathrm{d}, 50,000 \mathrm{~m}^{3} / \mathrm{d}, 90,000 \mathrm{~m}^{3} /$ $\mathrm{d}$, and $120,000 \mathrm{~m}^{3} / \mathrm{d}$.

This study proves that the model can optimize the layout of modular equipment, make the modular equipment run efficiently and economically, and reduce costs and increase efficiency, providing a reference for optimizing the equipment management strategy and promoting green production practice of shale gas production. An interesting topic is to investigate modular equipment dynamic allocation among multiple gas fields. In the future, we will carry out new research to propose an MILP optimization model to make the dynamic scheduling of modular equipment in the whole life cycle of shale gas development.

\section{DATA AVAILABILITY STATEMENT}

The original contributions presented in the study are included in the article/supplementary material; further inquiries can be directed to the corresponding authors.

\section{AUTHOR CONTRIBUTIONS}

$\mathrm{BH}$ and $\mathrm{XL}$ provided the idea. $\mathrm{BH}, \mathrm{XC}$, and $\mathrm{JGa}$ designed the research. $\mathrm{BH}$ and JGo carried out the literature search. $\mathrm{BH}, \mathrm{YL}$, and HL drafted the manuscript. All authors contributed to the article and approved the submitted version. 


\section{FUNDING}

This work was supported by the National Science and Technology Major Project of China (2016ZX05066005001), National Natural Science Foundation of China

\section{REFERENCES}

Arora, P., Hoadley, A. F. A., Mahajani, S. M., and Ganesh, A. (2016). SmallScale Ammonia Production from Biomass: A Techno-Enviro-Economic Perspective. Ind. Eng. Chem. Res. 55, 6422-6434. doi:10.1021/ acs.iecr.5b04937

Baldea, M., Edgar, T. F., Stanley, B. L., and Kiss, A. A. (2017). Modular Manufacturing Processes: Status, Challenges, and Opportunities. Aiche J.. 63, 4262-4272. doi:10.1002/aic.15872

Demirel, S. E., Li, J., and Hasan, M. M. F. (2017). Systematic Process Intensification Using Building Blocks. Comput. Chem. Eng. 105, 2-38. doi:10.1016/ j.compchemeng.2017.01.044

Fan, D., Gong, J., Zhang, S., Shi, G., Kang, Q., Xiao, Y., et al. (2021). A Transient Composition Tracking Method for Natural Gas Pipe Networks. Energy 215, 119131. doi:10.1016/j.energy.2020.119131

Gao, J., and You, F. (2017a). Can Modular Manufacturing Be the Next GameChanger in Shale Gas Supply Chain Design and Operations for Economic and Environmental Sustainability?. ACS Sust. Chem. Eng. 5, 10046-10071. doi:10.1021/acssuschemeng.7b02081

Gao, J., and You, F. (2017b). Design and Optimization of Shale Gas Energy Systems: Overview, Research Challenges, and Future Directions. Comput. Chem. Eng. 106, 699-718. doi:10.1016/ j.compchemeng.2017.01.032

Hong, B., Li, X., Di, G., Li, Y., Liu, X., Chen, S., et al. (2019). An Integrated MILP Method for Gathering Pipeline Networks Considering Hydraulic Characteristics. Chem. Eng. Res. Des. 152, 320-335. doi:10.1016/ j.cherd.2019.08.013

Hong, B., Li, X., Di, G., Song, S., Yu, W., Chen, S., et al. (2020a). An Integrated MILP Model for Optimal Planning of Multi-Period Onshore Gas Field Gathering Pipeline System. Comput. Ind. Eng. 146, 106479. doi:10.1016/ j.cie.2020.106479

Hong, B., Li, X., Song, S., Chen, S., Zhao, C., and Gong, J. (2020b). Optimal Planning and Modular Infrastructure Dynamic Allocation for Shale Gas Production. Appl. Energ. 261, 114439. doi:10.1016/j.apenergy.2019.114439

Lier, S., and Grünewald, M. (2011). Net Present Value Analysis of Modular Chemical Production Plants. Chem. Eng. Technol. 34, 809-816. doi:10.1002/ ceat. 201000380
(51874323), Zhejiang Province Key Research and Development Plan (2021C03152), Zhoushan Science and Technology Project (2021C21011), and Science Foundation of Zhejiang Ocean University (11025090721), all of which are gratefully acknowledged.

Palys, M. J., Allman, A., and Daoutidis, P. (2019). Exploring the Benefits of Modular Renewable-Powered Ammonia Production: A Supply Chain Optimization Study. Ind. Eng. Chem. Res. 58, 5898-5908. doi:10.1021/ acs.iecr.8b04189

Shi, B., Song, S., Chen, Y., Duan, X., Liao, Q., Fu, S., et al. (2021). Status of Natural Gas Hydrate Flow Assurance Research in China: A Review. Energy Fuels 35, 3611-3658. doi:10.1021/acs.energyfuels.0c04209

Tian, Y., Demirel, S. E., Hasan, M. M. F., and Pistikopoulos, E. N. (2018). An Overview of Process Systems Engineering Approaches for Process Intensification: State of the Art. Chem. Eng. Process. - Process Intensification 133, 160-210. doi:10.1016/j.cep.2018.07.014

Yang, M., and You, F. (2018). Modular Methanol Manufacturing from Shale Gas: Techno-economic and Environmental Analyses of Conventional Large-scale Production versus Small-scale Distributed, Modular Processing. Aiche J. 64, 495-510. doi:10.1002/aic.15958

Yin, L., He, M.-L., Xie, W.-B., Yuan, F., Chen, D.-B., and Su, Y. (2018). A Quantitative Model of Universalization, Serialization and Modularization on Equipment Systems. Physica A: Stat. Mech. its Appl. 508, 359-366. doi:10.1016/ j.physa.2018.05.120

Zhou, J., Peng, J., Liang, G., and Deng, T. (2019). Layout Optimization of Tree-Tree Gas Pipeline Network. J. Pet. Sci. Eng. 173, 666-680. doi:10.1016/ j.petrol.2018.10.067

Conflict of Interest: JG is employed by Sinopec Qingdao Refining and Chemical Co. Ltd. YL is employed by the China National Oil and Gas Exploration and Development Corporation.

The remaining authors declare that the research was conducted in the absence of any commercial or financial relationships that could be construed as a potential conflict of interest.

Copyright (c) 2021 Hong, Li, Cui, Gao, Li, Gong and Liu. This is an open-access article distributed under the terms of the Creative Commons Attribution License (CC $B Y)$. The use, distribution or reproduction in other forums is permitted, provided the original author(s) and the copyright owner(s) are credited and that the original publication in this journal is cited, in accordance with accepted academic practice. No use, distribution or reproduction is permitted which does not comply with these terms. 